\title{
Therapeutic effect of dental pulp stem cell transplantation on a rat model of radioactivity-induced esophageal injury
}

\author{
Chunwei Zhang ${ }^{1}$, Yichi Zhang', Zhenning Feng', Feifei Zhang ${ }^{1}$, Zishuai Liu', Xiaoli Sun', Mengting Ruan', \\ Mingna Liu ${ }^{1}$ and Shizhu Jin ${ }^{1}$
}

\begin{abstract}
Dental pulp stem cell (DPSC) transplantation has been demonstrated to promote the regeneration and repair of tissues and organs and is a potentially effective treatment for radioactive esophageal injury. In this study, to explore the therapeutic effects of DPSCs on acute radiation-induced esophageal injury, DPSCs were cultured and transplanted into rats with acute radioactive esophageal injuries induced by radioactive ${ }^{125}$ I seeds in vivo. In the injured esophagus, PKH26-labeled DPSCs co-localized with PCNA, CK14, CD71, and integrin a6, and the expression levels of these four makers of esophageal stem cells were significantly increased. After DPSC transplantation, the injured esophagus exhibited a greater thickness. In addition, the esophageal function and inflammation recovered faster. The results demonstrated that transplanted DPSCs, which trans-differentiated into esophageal stem cells in vivo, could repair the damaged esophageal tissue.
\end{abstract}

\section{Introduction}

Currently, chemoradiotherapy is the established standard treatment for locally advanced tumors of the head, neck, and lung. However, severe toxicities, such as acute radioactive esophageal injury, can develop within 3 weeks of radiation therapy and often cause unexpected complications ${ }^{1,2}$. Although natural radioprotectors are clinically used to prevent radiation injury, ionizing radiation injuries are not completely avoided ${ }^{3}$. Repeated ionizing radiation causes dysphagia and odynophagia, which may lead to weight loss, when radiation dosages exceed $30 \mathrm{~Gy}^{1-4}$. Although acute radioactive esophageal injury is usually self-limited, severe esophageal injury can greatly lengthen the treatment period through additional hospitalization, esophageal ulceration, and clinical symptoms that include difficulty in swallowing, odynophagia, and substernal pain. Late-onset damage includes esophageal stricture, sclerosis, and

Correspondence: Shizhu Jin (drshizhujinsci@126.com)

'Department of Gastrointestinal and Hepatology, The Second Affiliated Hospital, Harbin Medical University, Heilongjiang, Harbin, China

Edited by D. Aberdam. tracheoesophageal fistula, which seriously impact a patient's quality of life and long-term survival ${ }^{5}$. Acute radioactive esophageal injury is generally treated symptomatically with chemical agents ${ }^{6,7}$. Some of these agents, including amifostine, manganese superoxide dismutase-plasmid liposome, glutamine, recombinant human granulocytemacrophage colony-stimulating factor and epidermal growth factor, have been reported to relieve radiation injuries in clinical and preclinical settings ${ }^{8,9}$. Recently, research interest in stem cell (SC) transplantation to treat tissues and organs damage has greatly increased. Several studies on the use of mesenchymal cells derived from tissues and organs have been published ${ }^{10-12}$. Furthermore, the use of isolated progenitor cells or SCs for regenerating irradiation-damaged tissues has achieved great progress in recent years. As shown in the study by Epperly et al. ${ }^{13}$, the injection of bone marrow SCs into the mouse esophagus promoted the healing of the injured esophageal tissue, and localized cells with homing capacities could undergo unlimited proliferation in the irradiation-injured recipient esophagus. Compared to bone marrow SCs and other SCs,

\section{(c) The Author(s) 2018}

(c) (i) Open Access This article is licensed under a Creative Commons Attribution 4.0 International License, which permits use, sharing, adaptation, distribution and reproduction c. in any medium or format, as long as you give appropriate credit to the original author(s) and the source, provide a link to the Creative Commons license, and indicate if changes were made. The images or other third party material in this article are included in the article's Creative Commons license, unless indicated otherwise in a credit line to the material. If material is not included in the article's Creative Commons license and your intended use is not permitted by statutory regulation or exceeds the permitted use, you will need to obtain permission directly from the copyright holder. To view a copy of this license, visit http://creativecommons.org/licenses/by/4.0/. 

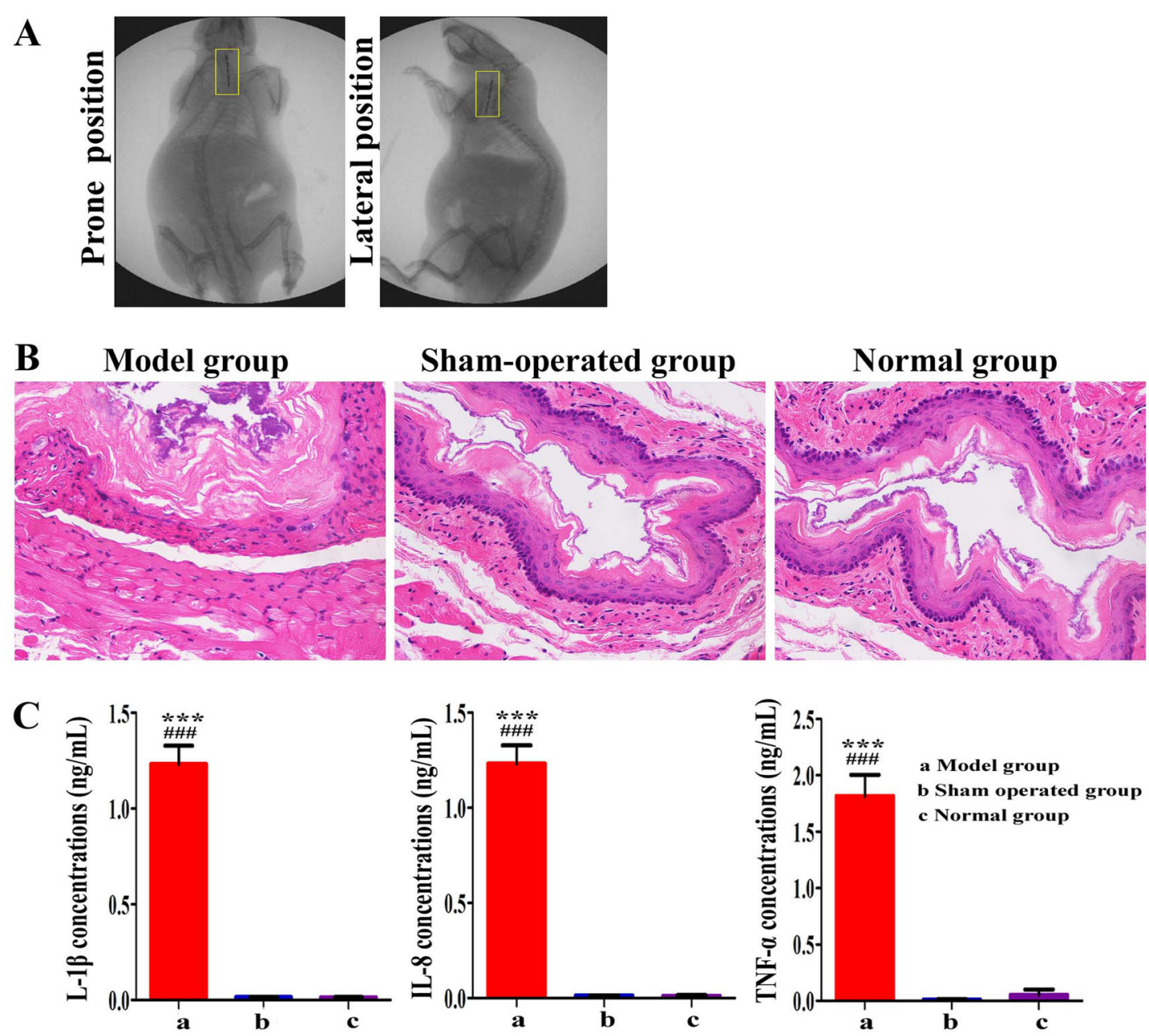

Fig. 1 Evaluation of the model. a X-ray revealed that the ${ }^{125} \mathrm{I}$ seed strain lined up in the esophageal lumen from the prone and lateral position. b Histological images showing esophageal tissue from the model, sham-operated and normal groups. The polygon cells and basal cells of the mucosa were arranged in a disorderly manner. Moreover, fractures, defects. and blood vessel congestion were observed. The lamina propria and submucosa were infiltrated by neutrophils and lymphocytes in the model group. However, the esophageal epithelium was well organized in the sham-operated and control groups ( $\times 100)$. c TNF-a, IL-1 $\beta$, and IL-8 concentrations were significantly increased in the model group compared with those in the control and sham-operated groups on the fourth day after radiation $(P<0.0001)$. Moreover, there were no significant differences between the control and sham-operated groups $(P>0.05)$. ${ }^{*} P<0.05$, ${ }^{* *} P<0.001$, ${ }^{* * *} P<0.0001$, the model group compared with the sham-operated group. ${ }^{\#} P<0.05,{ }^{\# \#} P<0.001,{ }^{\# \#} P<0.0001$, the model group compared with the normal group

dental pulp SCs (DPSCs) have additional advantages. DPSCs, a type of mesenchymal cell, have high proliferative capacity and can differentiate into osteoblasts, odontoblasts, adipocytes, neuronal cells, vascular cells, muscular cells, and epithelial cells ${ }^{14-17}$. The harvesting of dental SCs from extracted teeth has significant benefits compared with the harvesting of other SCs and other adult SCs, which require more invasive procedures that usually involve pain and the risk of adverse events. DPSCs are easily harvested from wisdom teeth, which are extracted worldwide and disposed of as medical waste; consequently, the study and application of DPSCs involve minimal ethical issues ${ }^{18-20}$. Moreover, DPSCs have been shown to be an efficient cell source for the treatment of many diseases ${ }^{21,22}$. Therefore, DPSCs provide an alternative ancestral cell source for regenerating the esophageal tissue via cell banking and could become a potential therapy for the treatment of radioactive esophageal injury.

The objective of this study was to evaluate the effects of DPSC implantation on the treatment of acute radioactive esophageal injury. We established an acute radioactive esophageal injury model to determine the effects of DPSC transplantation on esophageal tissue regeneration. ${ }^{125} \mathrm{I}$ seeds were used to irradiate the esophageal tissue in this model; the ${ }^{125}$ I seeds were placed in a disposable ureteral catheter and inserted into the esophageal lumen. In the present study, the model was induced by ${ }^{125}$ I seeds in vivo, differing from the previous in vitro methods. To the best 


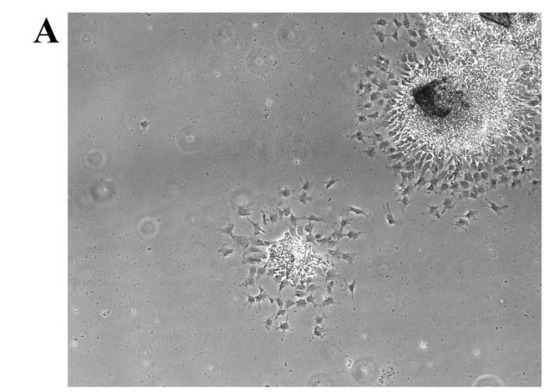

D

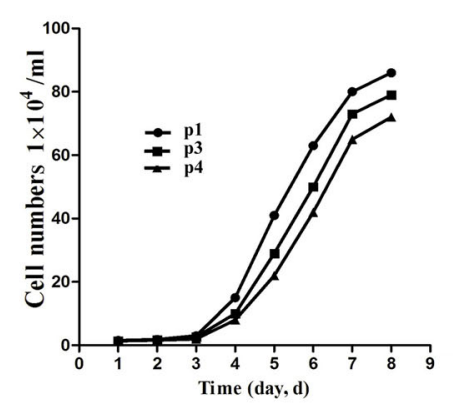

$\mathbf{G}$
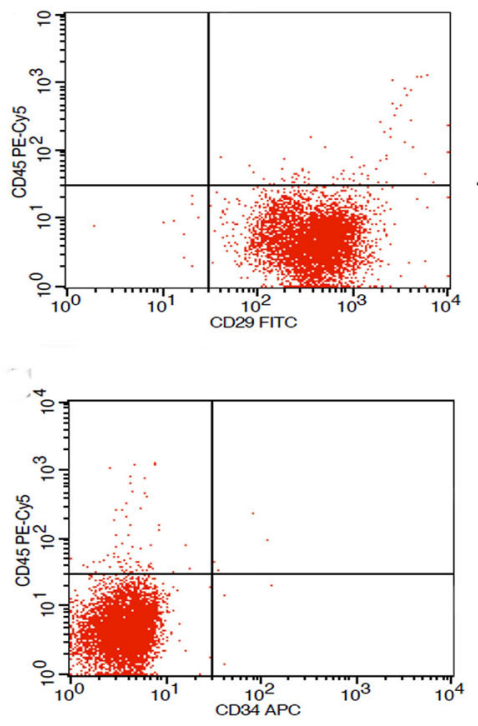

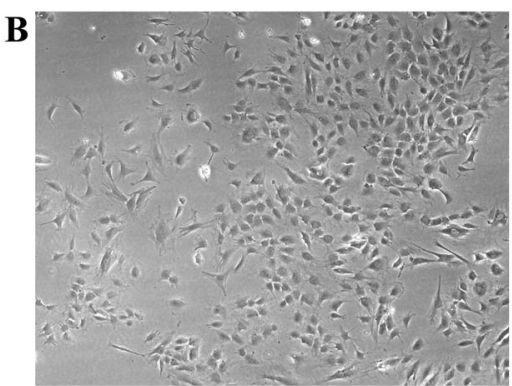

$\mathbf{E}$

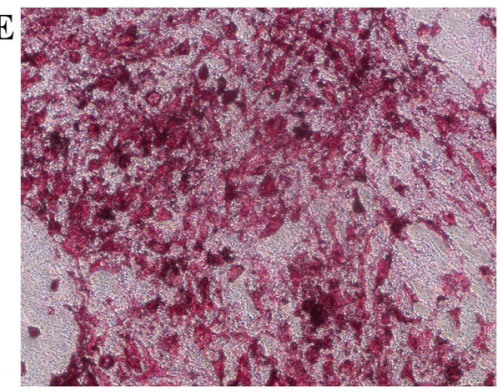

$\mathbf{F}$
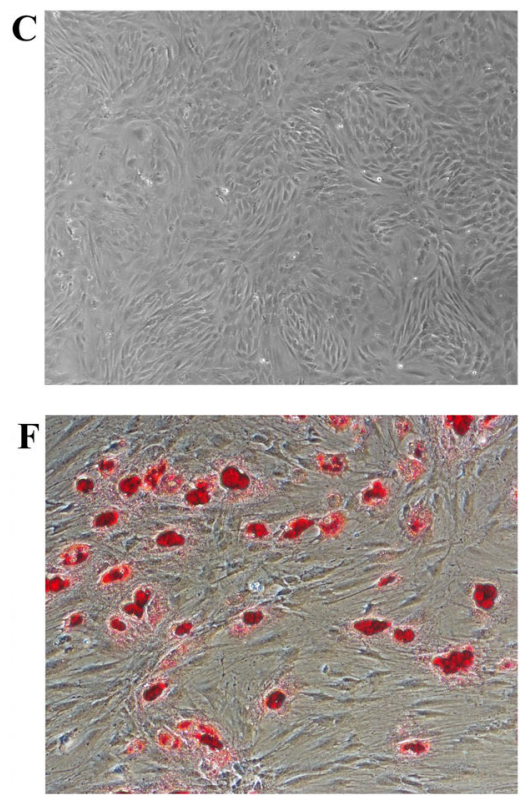

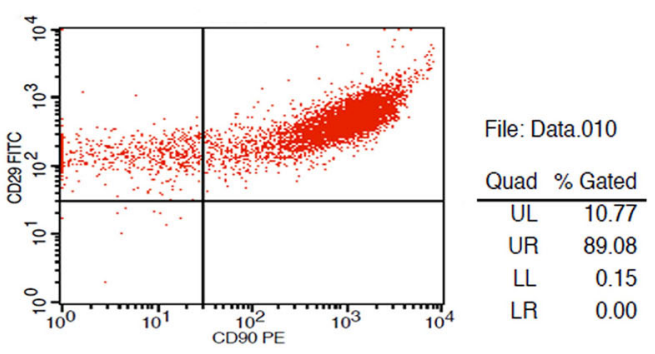

File: Data. 010
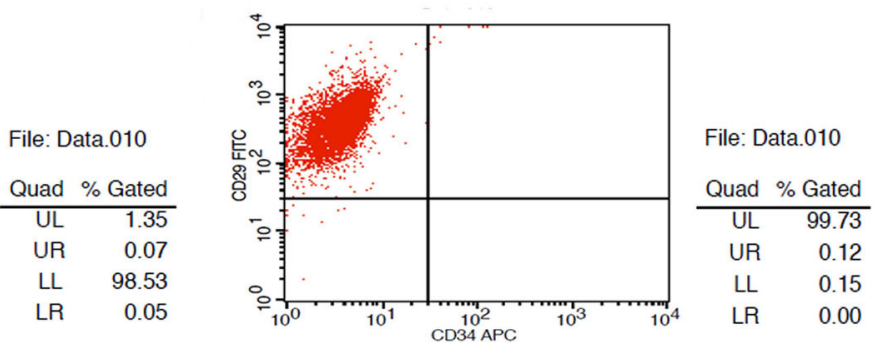

Fig. 2 Morphological features of DPSC growth and flow cytometric analyses with DPSC markers. a Primary DPSCs assumed a fibroblast-like appearance on the first day $(\times 40)$. b A large number of spindle cells attached to the culture dish on the fourth day $(\times 40)$. c The majority (80-90\%) of the DPSCs were confluent after 2 weeks $(\times 40)$. $\mathbf{d}$ On days $1-3$, the P1, P3, and P4 DPSCs proliferated slowly, and the cells appeared to proliferate rapidly from day 4 , entering the logarithmic phase. The increase in the number of cells then slowed gradually, reaching the plateau phase on day 8. e, $\mathbf{f}$ The DPSCs differentiated into the osteogenic and adipogenic lineages $(\times 100)$. $\mathbf{g}$ A total of $99.85 \%$ of the cells reacted with anti-rat CD29; $89.08 \%$ of the cells reacted with anti-rat CD90; $1.42 \%$ of the cells reacted with anti-rat CD45; and $0.12 \%$ of the cells reacted with anti-rat CD34

of our knowledge, the method used in the present study is the first of its kind to be described.

\section{Results}

Verification of the ${ }^{125} \mathrm{I}$ seed-induced radiation injury in the esophagus

${ }^{125}$ I seeds were successfully placed in a predetermined location in the esophageal lumen. Using the X-ray positioner, we observed ${ }^{125}$ I seeds lined up in the esophageal lumen along the long axis (Fig. 1a). The vertical distance between the esophageal lumen and each ${ }^{125}$ I seed was $0.05 \mathrm{~mm}$ in this experimental model, and the center point of the seed dose rate was $43 \mathrm{cGy} / \mathrm{h}$, according to the formula $\dot{D}(r, \theta)=N \Sigma \dot{D}\left(r_{\mathrm{i}}, \theta_{\mathrm{i}}\right)^{23,24}$. Using the naked eye, we also observed that the esophageal mucosa became swollen after 5 days of exposure to radiation in the model group. 
The polygon cells and basal cells of the mucosa showed a disordered arrangement. Moreover, the fractures, defects, and blood vessel congestion had noticeably increased. The lamina propria and submucosa were infiltrated by inflammatory cells containing neutrophils and lymphocytes, and the thickness of the esophageal epithelium was obviously reduced. In the normal and sham-operated groups, the basal compartment of the rat esophageal epithelium consisted of a single row of densely packed cuboidal cells whose oval nuclei were oriented toward the lumen and were deeply basophilic. The suprabasal compartment included multiple layers of polyhedral cells with spherical nuclei, above which existed a granular layer that was equal to the esophageal epithelial surface of the degenerating nuclei. The lamina propria contained collagen fibers composed of fibroblasts, and the muscular layer contained internal circular muscles and external longitudinal muscles (Fig. 1b). The inflammatory cytokine levels of the rats in the model, sham-operated and control groups were compared. Compared with the normal and sham-operated groups on the fourth day after radiation, the model group exhibited significantly higher interleukin-1 $\beta$ (IL-1 $\beta)$, IL- 8 , and tumor necrosis factor- $\alpha$ (TNF- $\alpha)$ concentrations $(P<0.0001)$, and significant differences were not observed between the normal and sham-operated groups $(P>0.05)$ (Fig. 1c).

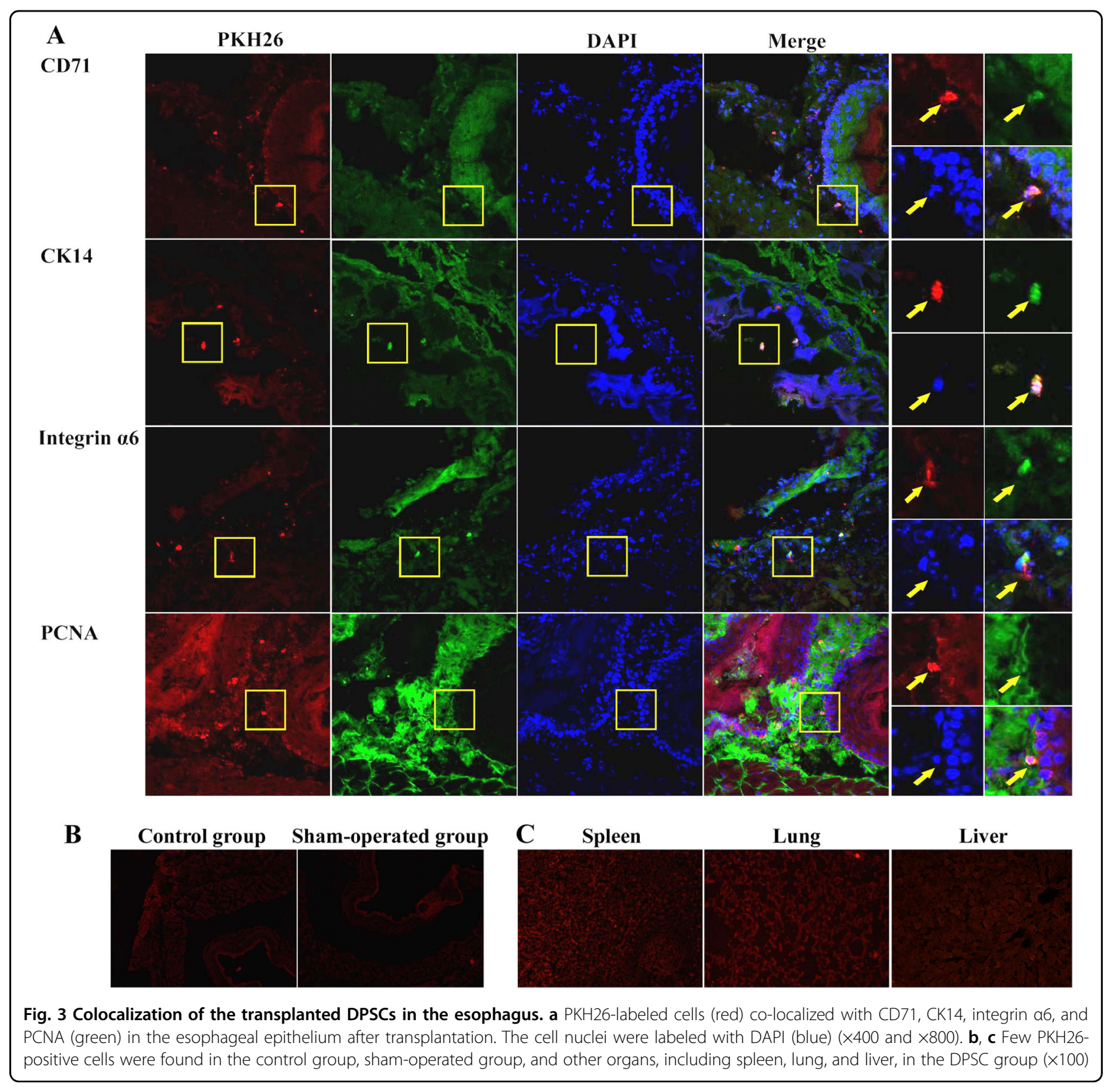




\section{Characterization of the isolated DPSCs}

The DPSCs isolated from the incisors were cultured in dishes, early passage (P0) cells appeared triangular, polygonal, or spindle shaped when they began to stick to the bottom of the dish and form spindles (Fig. 2a), most of which were present after 4 days, exhibiting radial or spiral growth (Fig. 2b). Colony formation was observed between 5 and 6 days, and the cells appeared to confluence at 7-8 days. The DPSCs were removed from the petri dishes using trypsin, transferred into flasks, and amplified for the following 2 weeks (Fig. 2c).

The P1, P3, and P4 DPSCs in the latent phase proliferated slowly on days $1-3$. SC colonies were observed on day 3 , and the cells appeared to proliferate rapidly from day 4 onward and entered the logarithmic phase. The cell number then slowed down gradually, reaching the plateau phase on day 8 (Fig. 2d). According to the growth curve, P3 cells were selected.

Osteogenic differentiating cultures were determined based on a positive red area of mineralized matrix stained with alizarin red (Fig. 2e). Adipogenic differentiation was determined by the presence of lipid droplets stained red with Oil Red O (Fig. 2f).

Fluorescence-activated cell sorting (FACS) analysis was used to determine the expression levels of the specific DPSC antigen markers. In total, $99.85 \%$ of the expanded cells expressed CD29, and $89.08 \%$ of the cells expressed CD90. In contrast, $1.42 \%$ expressed CD45, a hematopoietic cell and leukocyte marker ${ }^{25}$, and only $0.12 \%$ expressed CD34, a dental pulp progenitor cell antigen that also appears on some epithelial cells and fibroblasts (Fig. 2g) ${ }^{26,27}$. Thus, the dental pulp cells extracted from the incisors of the Sprague-Dawley (S-D) rats were mostly DPSCs.

\section{Colocalization of the transplanted DPSCs in the esophagus}

The transplanted DPSCs' potential to proliferate and trans-differentiate into esophageal cells was evaluated for 4 weeks after cell transplantation. Some PKH26positive cells appeared to colocalize with CD71 by 4 weeks post transplant. The PKH26-positive cells also co-expressed CK14, integrin $\alpha 6$, and PCNA (Fig. 3a).

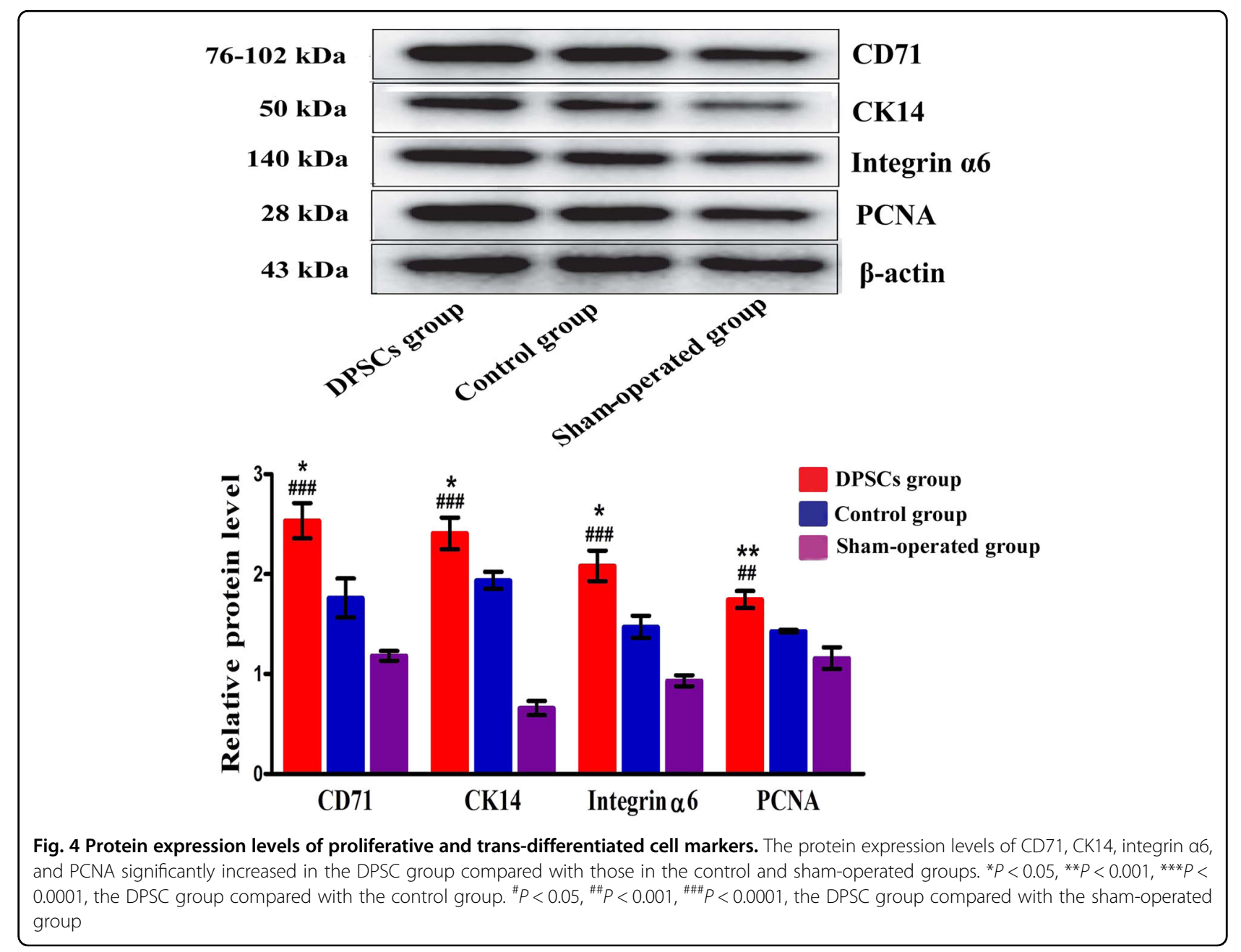


Many triple-labeled cells were located in pairs or small clusters of proliferating and differentiating cells. Furthermore, few PKH26-positive cells were found in the control group, the sham-operated group and other organs, including the spleen, lung, and liver, in the DPSC group (Fig. 3b).

\section{The characterization of DPSCs as proliferative and trans- differentiated cells}

Esophageal tissues from rats in all three groups were examined using Western blotting (WB) and immunohistochemistry to assess the proliferation and transdifferentiation of DPSCs into esophageal cell-like cells in the injured esophagus. We performed a quantitative analysis of the amounts of CD71, CK14, integrin $\alpha 6$, and PCNA in the DPSC, control, and sham-operated groups by measuring these protein levels and the mean optical density (MOD) of the area-of-interest (AOI). The levels of cell surface marker proteins in the DPSC group were significantly higher than those in the other two groups (Fig. 4). Additionally, positive cells were mostly located on the basal layer, as revealed by immunohistochemical staining. The MODs of the AOIs of four cell surface markers (CD71, CK14, integrin $\alpha 6$, and PCNA) in the DPSC group were significantly higher than those in the other two groups (Fig. 5).

\section{Improvements in the histological and inflammatory signs of radioactive esophageal injury following the infusion of DPSCs}

The thickness of the esophageal epithelium from the same levels of the rat esophageal segments were measured and compared among the DPSC group, the control group, and the sham-operated group (Fig. 6a). The mean epithelial thickness was significantly increased in the DPSC group $(62.35 \pm 1.99 \mu \mathrm{m})$ relative to the control group $(27.11 \pm 2.92 \mu \mathrm{m})$ and the sham-operated group $(25.71 \pm$ $1.90 \mu \mathrm{m}$; Fig. 6b). The IL- $1 \beta$, IL-8, and TNF- $\alpha$ levels in the DPSC group were not significantly different from those in the sham-operated group $(P>0.05)$. However, the TNF- $\alpha$, IL-1 $\beta$, and IL- 8 levels in the control group were higher than those in the DPSC and sham-operated groups $(P<$ 0.0001; Fig. 6c).

\section{Improvement in the esophageal function}

The DPSC and control groups basically underwent passive feeding and exhibited a worse condition and were less active than the sham-operated group after the ${ }^{125} \mathrm{I}$ seeds were removed. The average intake of each rat was analyzed daily. Over time, the food intake levels of every rat in the DPSC and control groups gradually increased, and there was a significant difference between the DPSC and control groups beginning on the sixth day. The recuperative extrema of food intake in the DPSC group was significantly higher than that in the control group $(P<0.0001$; Fig. 7).

\section{Discussion}

After irradiation, the esophageal mucosa undergoes hyperemia and edema, leading to a series of complications, such as dysphagia, local pain, and retrosternal burning sensations ${ }^{2}$. These symptoms in turn can cause inadequate food intake, unbearable pain, malnutrition, and electrolyte disorders. Eventually, patients must stop radiotherapy before the duration recommended for optimal recovery is achieved ${ }^{28}$. Both supportive and symptomatic therapies are traditionally used to treat these complications. However, as SC research advances in the medical field, SC transplantation for treating radiationinduced esophageal damage has been explored as a new research direction. DPSCs are capable of homing, proliferation, and differentiation in injured tissue ${ }^{23,29,30}$.

In the present study, the SC source was DPSCs. Isolated DPSCs must be expanded before the SCs are transplanted. In the present study, most of the expanded DPSCs expressed CD90 and CD29, whereas few expressed CD45 and CD34. This result meets the defined standard of DPSCs established in previous studies ${ }^{31}$.

According to Epperly ${ }^{13}$, bone marrow cells also have the capacity to engraft on and differentiate into squamous cells in the irradiated esophagus. Although bone marrow cells and DPSCs display a similar capacity for differentiation, harvesting SCs from extracted teeth presents significant advantages compared with harvesting cells from bone marrow ${ }^{32,33}$ and the harvesting of other adult $\mathrm{SCs}$ that require more invasive procedures. DPSCs can be easily obtained from wisdom teeth, and there are minimal ethical issues involved in the use of DPSCs. Hence, tooth banking is an important step in future tissue engineering. Given these advantages, this study chose to investigate the use of DPSCs ${ }^{18-20}$. Meanwhile, SCs were transplanted via a vein in this study; this method has the advantage of being simple, widely applicable, safe, feasible, and highly effective. Directing the site-specific differentiation of DPSCs demands an accurate animal model, and the previous methods used to create animal models mainly relied on external exposure ${ }^{34,35}$ and the use of a higher radiation dose rate to administer a large amount of radiation to the radiation field within a short period. The irradiation was large for these rats, and the mortality was high. The exposed fields in the conventional methods were the neck and chest; thus, injury to the surrounding tissues was inevitable, so the in vitro model was not accurate. Therefore, we designed a new model in which ${ }^{125}$ I seeds placed in a disposable ureteral catheter were applied to irradiate the esophageal lumen in vivo. Since the disposable ureteral catheter could induce physical side injury to the esophageal cavity during the process, a 


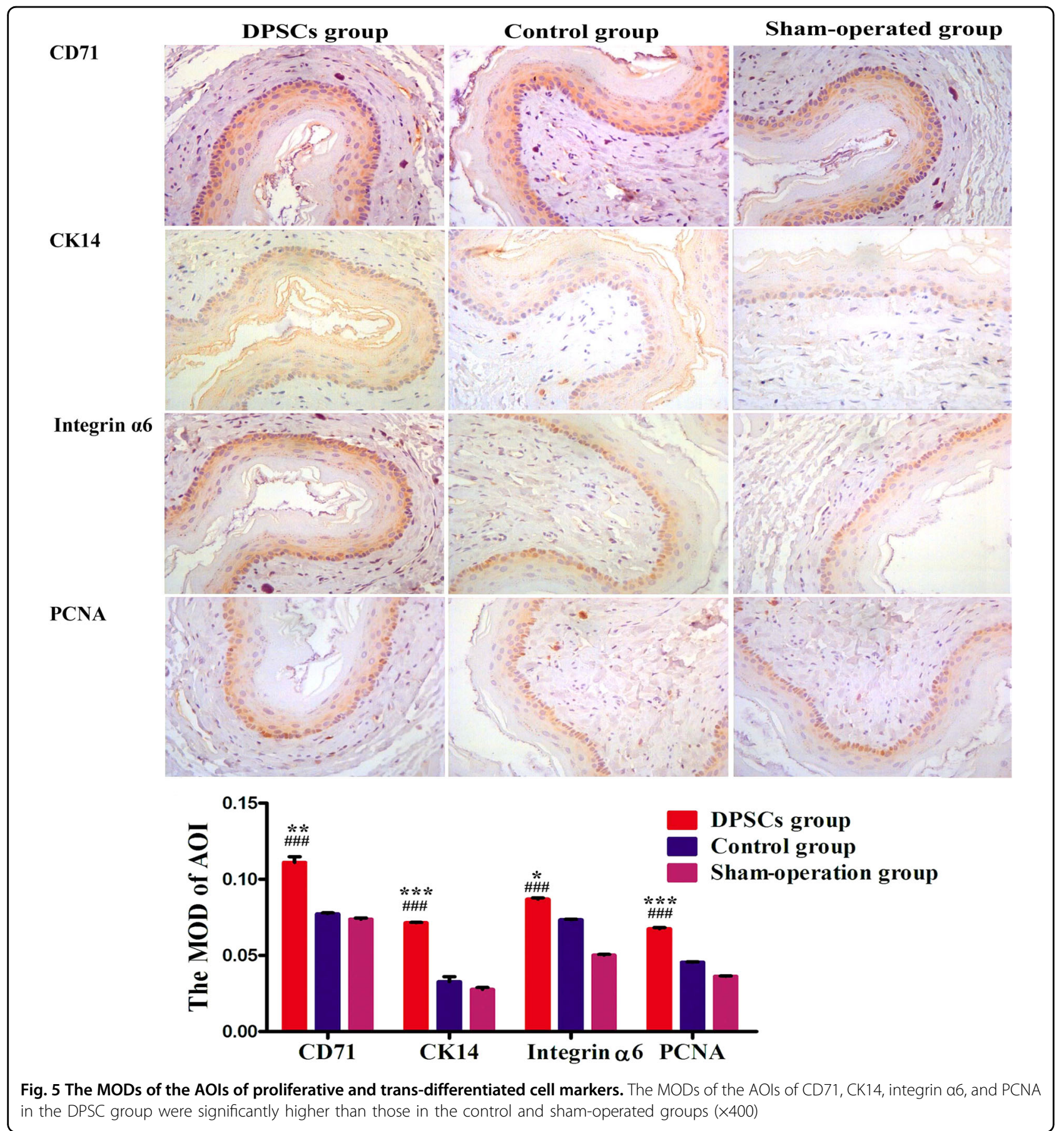

sham-operated group was designed in which only the catheter lacking ${ }^{125}$ I seeds was inserted into the esophagus. Rats in the sham-operated group showed wellorganized tissues and good food intake, similar to the normal group in the present study; thus, the possibility of catheter-induced damage was excluded. In the acute radiation esophagitis model (the model group) used in the present study, we observed radioactive damage similar to that described in previous studies ${ }^{36}$. In this model, which was induced by ${ }^{125}$ I seeds in vivo, the lumen of the esophagus was first irradiated, and the mucosa developed congestion, edema, inflammatory effusion, and exfoliation; meanwhile, inflammatory cytokines, including TNF$\alpha$, IL-1 $\beta$, and IL- 8 , were released. The epithelium became thin, necrotic, and denuded. These changes induced dysphagia, odynophagia, and retrosternal pain. These symptoms and pathological changes are similar to those of acute clinical radioactive esophagitis ${ }^{1,2,37} \cdot{ }^{125}$ I seeds 

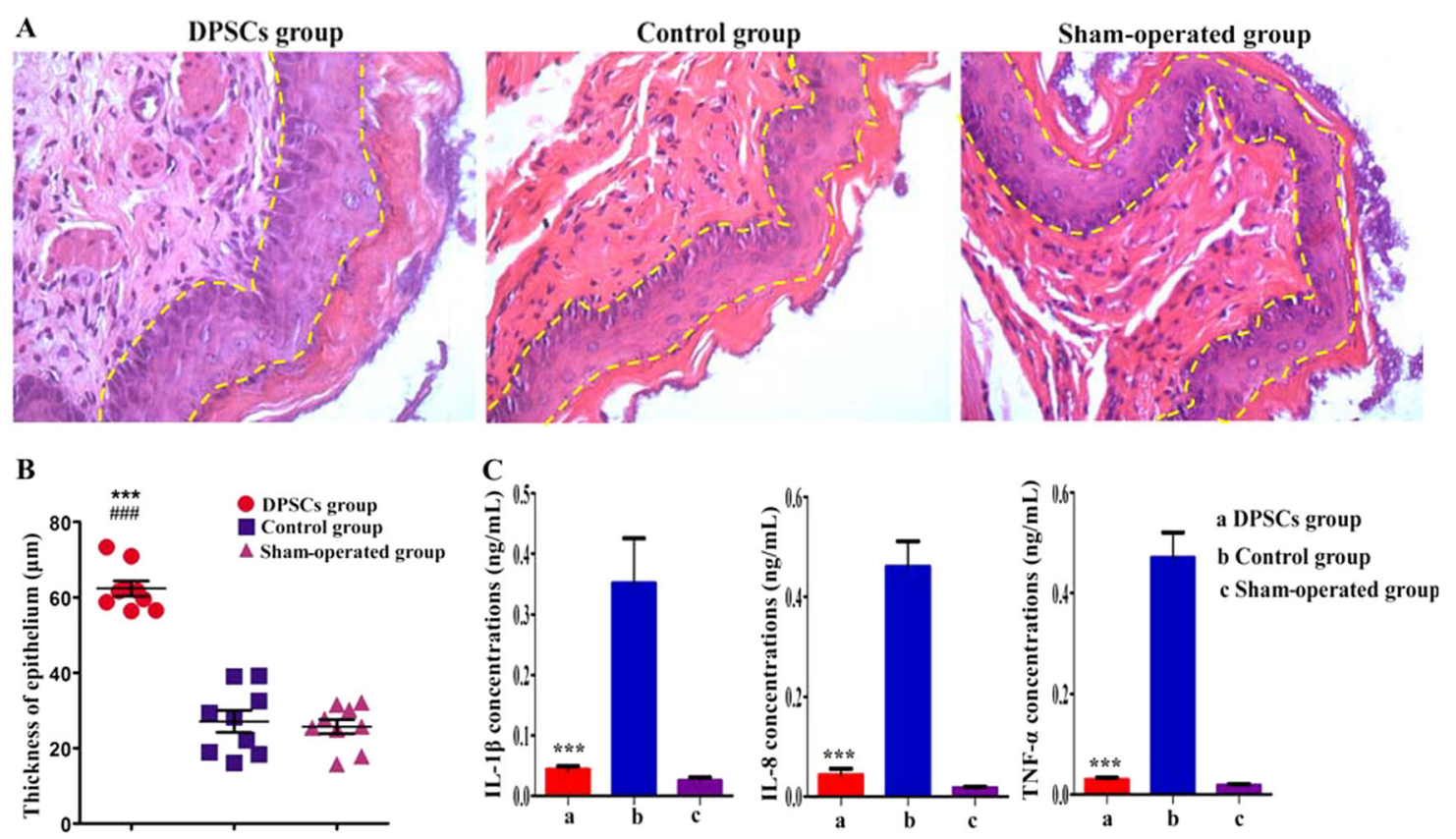

Fig. 6 Histological and inflammatory improvements in radioactive esophageal injury with infused DPSCs. $\mathbf{a}$, $\mathbf{b}$ The histological images of the esophagus revealed that the thickness of the epithelium in the DPSC group was significantly increased compared with those in the control and sham-operated groups $(\times 400)$. c The TNF- $\alpha, I L-1 \beta$, and IL-8 concentrations in the DPSC group were not significantly different from those in the shamoperated group $(P>0.05)$. The TNF- $a, I L-1 \beta$, and IL-8 concentrations in the control group were higher than those in the DPSC and sham-operated groups $(P<0.0001)$. ${ }^{*} P<0.05$, ${ }^{*} P<0.001$, and ${ }^{* * *} P<0.0001$, the DPSC group compared with the control group. ${ }^{\#} P<0.05$, ${ }^{\# \#} P<0.001$, and ${ }^{\# \# \#} P<$ 0.0001 , the DPSC group compared with the sham-operated group

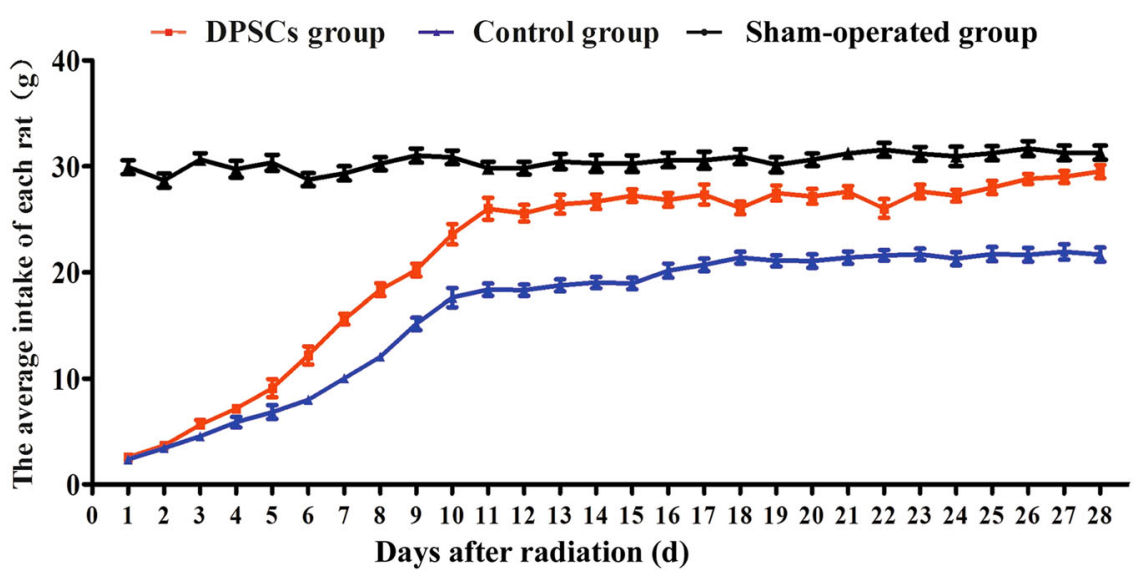

Fig. 7 Average daily food intake levels of rats in all groups. The rats with DPSC treatment showed better food intake recovery; the food intake in the DPSC group was significantly higher than that in the control group from the sixth day forward, and the food intake in the DPSC group gradually approached the normal level

provide low doses of radiation that quickly decrease with increasing distance ${ }^{38}$. The outer membrane displayed less damage in this model; hence, stricture and sclerosis were rarely observed. Moreover, the ${ }^{125}$ I seeds caused less damage to surrounding tissues over a short time. ${ }^{125} \mathrm{I}$ seeds are widely used clinically and are easily obtained.
${ }^{125}$ I seeds as the low dose rate radioactive source are relatively safe for the rats with a low mortality rate ${ }^{37,39,40}$. These advantages allowed us to perform irradiation in vivo using this technique.

PKH26, a red fluorescent dye that labels the SC membrane, has a fast dyeing speed, stable properties, and no 
cytotoxicity ${ }^{41}$. PKH26 also glows red under a 551-nm excitation light, is observable using a fluorescence microscope, and is allocated to the daughter cells after DPSC differentiation. In the present study, DPSCs that were amplified in vitro were effectively labeled with PKH26 and were tracked in the rats' bodies after transplantation.

The transplantation of DPSCs appeared to relieve the impairments in esophageal function in the rats with acute radioactive esophageal injury, as indicated by their increased food intake. The food intake of the DPSC group was significantly increased compared with the control group beginning on the sixth day. Similar to the functional improvement of acute radioactive esophageal injuries in rats treated with DPSCs, the same treatment significantly improved the radioactive damage to the esophageal epithelium. In addition, the degree of inflammation was significantly relieved in the DPSC group, as evidenced by the TNF- $\alpha$, IL- $1 \beta$, and IL- 8 levels. After irradiation, the cells may release a malignant signal or chemical substance that stimulates DPSC homing and engraftment onto the injured esophageal tissue through the blood circulation. Then, the trans-differentiation and proliferation of the DPSCs increase the thickness of the esophageal epithelium ${ }^{42,43}$. These results provide new evidence of the therapeutic efficacy of DPSCs for treating acute radioactive esophageal injury. In the DPSC-treated rats, transplanted PKH26-labeled cells were found in the injured areas of the esophagus. These cells co-localized with PCNA, a nuclear antigen related to and synthesized during the cell cycle ${ }^{44}$, indicating that they proliferated in the esophagus. Furthermore, the transplanted DPSCs expressed CD71 and integrin $\alpha 6$, two cell surface markers used to identify putative SCs in the rat epidermis ${ }^{45,46}$. As shown in the study by Croagh et al ${ }^{45}$, the $\alpha^{\text {bri }} C^{\text {bri }}$ cells represent a transit-amplifying population. These cells were the direct progeny of SCs, as they became a pool of dividing cells that increased to create differentiating suprabasal compartments. Moreover, the transplanted DPSCs co-localized with CK14, a squamous epithelial marker ${ }^{47}$. Based on the immunofluorescence (IF) staining, the transplanted DPSCs homed to the injured esophagus, where they may have proliferated and trans-differentiated into the esophageal SCs that repaired the injured mucosa of the DPSC-treated rats in vivo; the few PKH26-positive cells that were found in the spleen, lung, and liver indicated the slight injury in the tissue surrounding the esophagus. In the present study, the WB and immunohistochemical analyses revealed significantly higher expression levels of cell surface markers, including PCNA, CD71, integrin $\alpha 6$, and CK14, in the DPSC-treated group than those in the control and sham-operated groups. Thus, the transplanted DPSCs proliferated and trans-differentiated into mature esophageal epithelial cells in vivo and repaired the damaged esophageal tissue in the DPSC group. Some inflammatory factors were induced by and mediated primary esophageal epithelial proliferative responses to injury and regulated the healing of esophageal injuries in the control group; hence, the transdifferentiated cell makers were upregulated in the control group compared with those in the sham-operated group.

An obvious therapeutic effect of DPSC transplantation was observed on the 28th day in the present study. We observed the early behavior of DPSCs on the 7th, 14th, and 21st days; SC homing was found, but the trans-differentiation of DPSCs was not detected. The observations were extended to the 28th day, and transdifferentiation was widely detected. However, the experimental duration was too short to identify long-term complications of SC transplantation, including any carcinogenic changes. Further experiments are required to examine these complications in the future.

\section{Conclusions}

After expansion in vitro, transplanted DPSCs recognize the radioactive injury and home to the injured esophagus, where the cells proliferate and trans-differentiate into esophageal SCs to repair the damaged esophageal tissue in vivo. The interaction between DPSCs and their niche, especially the involvement of signaling pathways, requires further research. Based on their regenerative performance, DPSCs heal tissue damage and improve the esophageal function following acute radioactive esophageal injury in rats. The findings of the present study imply that DPSC transplantation is an alternative approach for the treatment of acute radioactive esophageal injury. We encourage further preclinical studies and clinical trials of the potential use of DPSC transplantation in patients with acute radioactive esophageal injury. Although most patients with acute radioactive esophageal injury originally had a malignant tumor, researchers have not determined whether DPSC transplantation might increase the risk of recurrence and treatment difficulties. The best time to prevent or treat acute radioactive esophageal injury and the use of individualized therapy also requires further research and discussion.

\section{Materials and methods \\ Experimental animals}

Thirty-three adult male S-D rats weighing $280-300 \mathrm{~g}$ and two additional male rats weighing approximately $200 \mathrm{~g}$ were obtained from the Animal Facility of the Second Affiliated Hospital of Harbin Medical University, China. The animals were maintained in rooms at a constant temperature and humidity $\left(23 \pm 1{ }^{\circ} \mathrm{C}, 75 \%\right)$ with a $12 / 12$-h light-dark cycle. The rats were then sterilized and given normal laboratory rat food ad libitum. All experimental animal protocols were approved by the Harbin Medical 

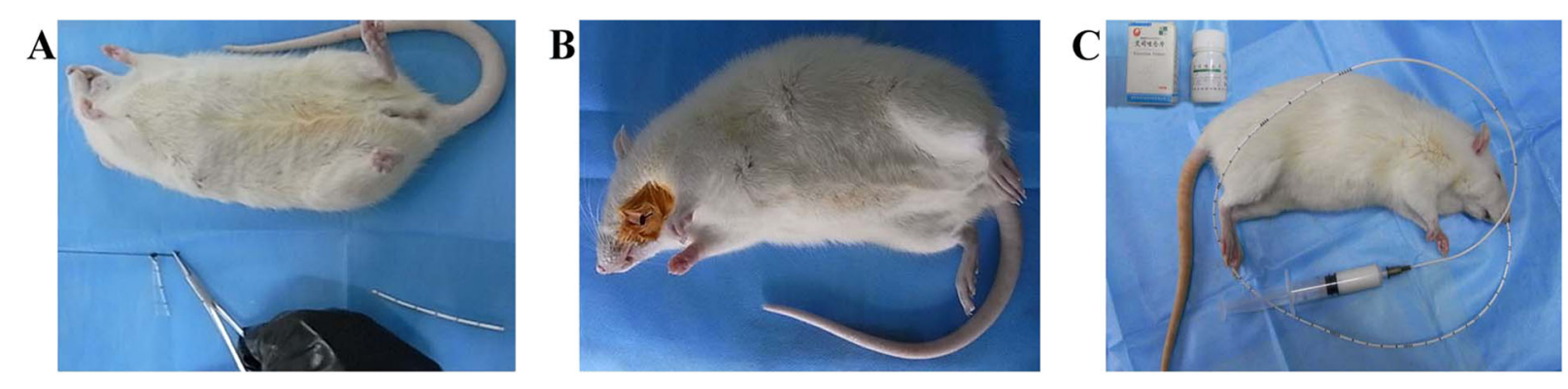

D
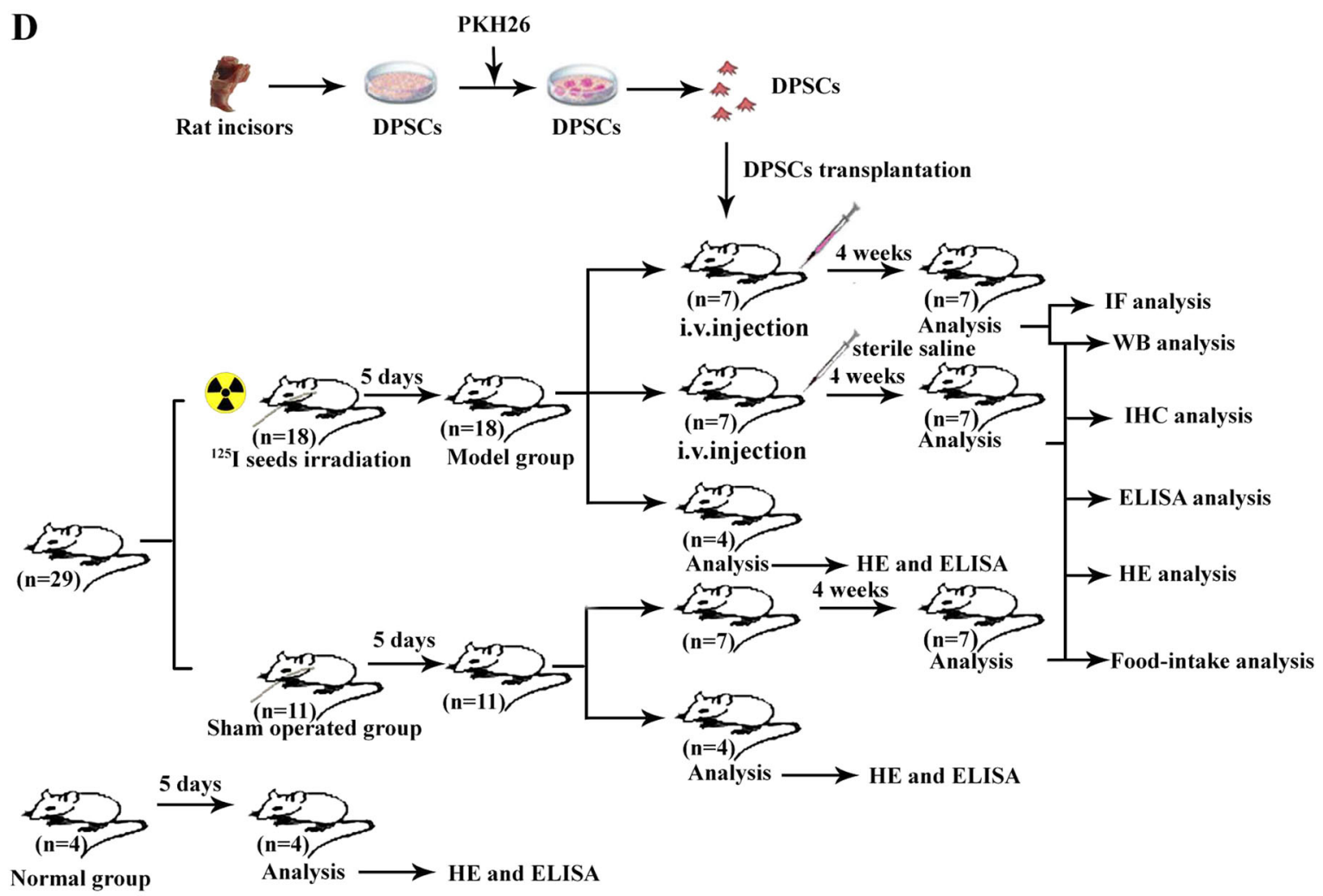

DPSCs transplantation

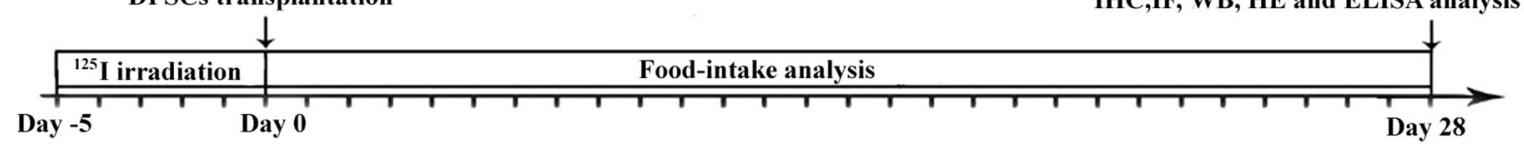

Fig. 8 The steps to produce an in vivo model. a Five ${ }^{125}$ seeds were placed close together in a disposable ureteral catheter, and the end of the catheter was stitched with a suture to secure the ${ }^{125} \mathrm{l}$. b The disposable ureteral catheter including the ${ }^{125} \mathrm{I}$ seeds was fixed in the oral cavity. $\mathbf{c}$ The rats were administered food and estazolam through a disposable ureteral catheter when they were irradiated. $\mathbf{d}$ The flow chart of this study

University Animal Care and Use Committee. All animals were treated under appropriate conditions according to the National Institute of Health Guidelines for the Care and Use of Experimental Animals.

\section{The isolation, culture, and differentiation of DPSCs}

DPSCs were derived from both the upper and lower incisors of two adult male S-D rats weighing approximately $200 \mathrm{~g}$ after euthanasia. The dental pulp tissues were removed and suspended in phosphate-buffered saline (PBS) including $0.1 \%$ collagenase and $0.25 \%$ trypsin-ethylenediaminetetraacetic acid. DPSCs were cultured in alpha modified Eagle's medium (GIBCO Laboratories, Inc., Grand Island, NY, USA) supplemented with $5.5 \mathrm{mmol} / \mathrm{L}$ glucose and $20 \%$ fetal bovine serum (FBS, Shanghai Solarbio, Shanghai, China) in an incubator at $37^{\circ} \mathrm{C}$ with saturated humidity and $50 \mathrm{~mL} / \mathrm{L} \quad \mathrm{CO}_{2}$. DPSCs of the first passage (P1), third passage (P3), and fourth passage (P4) in a good state were cultivated in 24well culture plates at a density of $1 \times 10^{9}$ cells $/ \mathrm{mL}$. The 
cell numbers were counted daily using a hemocytometer. Three wells were counted each day, the average numbers were calculated, and the values were used to plot a growth curve. The OriCell ${ }^{\mathrm{TM}}$ osteogenesis differentiation kit (Cyagen, Guangzhou, China) was used to induce osteogenic differentiation. P3 SCs were cultured in osteogenic differentiation medium and fed every 3 days for 3 weeks. The alizarin red working solution was used to stain the cells for 3 to $5 \mathrm{~min}$ for alizarin red staining. Adipogenesis was induced by using the OriCell ${ }^{\mathrm{TM}}$ adipogenic differentiation kit (Cyagen). The Oil Red $\mathrm{O}$ working solution (3:2 dilution with distilled water, filtered) was used to stain P3 SCs cultured in adipogenic differentiation medium for $30 \mathrm{~min}$ for Oil Red O staining. DPSCs (P3) were labeled with the fluorescent dye PKH26 (Sigma Aldrich, USA) following the manufacturer's instructions ${ }^{48}$.

\section{The experimental esophageal model and study design}

Four of the $33 \mathrm{~S}-\mathrm{D}$ rats from the normal group were randomly selected and omitted from any handling or procedures. Eighteen rats were then randomly selected from the remaining group and were irradiated using ${ }^{125} \mathrm{I}$ seeds (Beijing Atom Technology Co., Ltd., 6711, China) with an initial activity of $0.8 \mathrm{mCi}$ for 5 days. Next, the rats were anesthetized with $10 \%$ chloral hydrate $(0.3 \mathrm{~mL} / 100 \mathrm{~g}$, Gongsi) via intraperitoneal injection and were fixed on the board in the supine position. Five ${ }^{125} \mathrm{I}$ seeds were placed close together at a depth of $8 \mathrm{~cm}$ in a disposable ureteral catheter (Shanghai Kangge Medical Equipment Co., Ltd., production batch number: 101103, Specification: F4, China) using a guidewire passed through the oral cavity into the esophagus (Fig. 8a). The catheter was fixed in the oral cavity with a suture after the guidewire was removed (Fig. 8b). X-rays were obtained after the operation to confirm whether the ${ }^{125}$ I seeds were located in the rat's esophagus. The remaining rats were assigned to the shamoperated group, in which only a disposable ureteral catheter was placed into the esophagus. The rats $(n=29)$ were fed liquid diets through the catheter when they were awake. During feeding, the rats were also administered estazolam via the catheter to calm them (Fig. 8c). Four rats were randomly chosen from every group, euthanized on the fifth day, and the radiation injury was evaluated. The rats in the radioactive esophageal injury model group were randomly divided into two groups of seven rats each. The animals in the experimental group were injected with DPSCs $\left(1 \times 10^{7}\right.$ cells) via the tail vein, whereas the control group received sterile saline. The rats were regularly provided with food and water daily, and the food intake was assessed daily. Three groups of rats were euthanized on the fourth week after transplantation, and their esophageal tissues were removed to evaluate their recovery (Fig. 8d).

\section{Flow cytometry}

FACS was used to analyze the expression levels of the various antigen markers of cultured DPSCs ${ }^{49}$. SCs $(1 \times$ $10^{6}$ ) were incubated with $1 \mu \mathrm{L}$ of rat monoclonal antibodies against $\mathrm{CD} 90, \mathrm{CD} 29, \mathrm{CD} 45$, and CD34 (BD Bioscience, San Jose, $\mathrm{CA} ; 1 \mu \mathrm{L}$ ) in $2 \% \mathrm{FBS}$ at $4{ }^{\circ} \mathrm{C}$ for $30 \mathrm{~min}$. Cells from the negative control group were incubated in the buffer without any major antibodies. The fluorescence signals were analyzed using FACSCalibur Cell Quest software (Becton Dickinson, USA).

\section{Tissue preparation}

On the estimated date after irradiation and transplantation, the rats were sacrificed by myocardial perfusion with $4 \%$ paraformaldehyde dissolved in PBS after anesthesia with $10 \%$ chloral hydrate (intraperitoneally). The upper two-thirds of each esophagus were removed from the thorax and abdomen, rinsed with PBS, and immersed in $30 \%$ sucrose overnight at $4{ }^{\circ} \mathrm{C}$. The esophageal tissue was embedded in optimum cutting temperature compound (OCT) after freezing, prepared into frozen sections with a thickness of $6 \mu \mathrm{m}$, and mounted onto glass slides. The histological evaluation included hematoxylin and eosin (HE) staining of the first and last cuts of the serial sections, and sections selected at intervals of 20 were used for IF and immunohistochemical (IHC) staining.

\section{Immunohistochemistry}

IHC staining was performed as described previously ${ }^{50}$. Sections were submerged in $0.3 \%$ hydrogen peroxide methanol solution for $30 \mathrm{~min}$, incubated in PBS containing $5 \%$ normal horse serum and $0.3 \%$ Triton X-100 for $2 \mathrm{~h}$, and then incubated with PCNA, CK14, integrin $\alpha 6$, and CD71 primary antibodies overnight at $4{ }^{\circ} \mathrm{C}$. Sections were then kept at room temperature (RT) for $40 \mathrm{~min}$ and treated with pre-diluted biotinylated anti-mouse immunoglobulin secondary antibody for $2 \mathrm{~h}$ and avidin biotin complex reagent (1:400) for $1 \mathrm{~h}$. Immunoreaction was visible under $0.05 \%$ diaminobenzidine and $0.003 \% \mathrm{H}_{2} \mathrm{O}_{2}$. The sections were washed three times after incubation (10 min per wash), dried, dehydrated with ethanol gradient, washed with dimethylbenzene, mounted, and baked.

\section{Histological and IF staining}

The esophageal histological analysis using HE staining followed the established standard procedures ${ }^{51}$. IF staining was performed to examine the homing and differentiation of infused DPSCs in the esophageal tissue ${ }^{52}$. Sections of the esophagus were incubated in PBS containing 5\% normal donkey serum and mouse anti-PCNA antibody (1:100, Santa Cruz Biotechnology, BM0104), mouse anti-CK14 antibody (1:100, Abcam, ab49747), mouse anti-integrin $\alpha 6$ antibody (1:100, Santa Cruz 
Biotechnology, sc-13542) and mouse anti-CD71 antibody (1:200, AbD, MCA155R) overnight at $4{ }^{\circ} \mathrm{C}$. Sections were then washed with PBS and subsequently reacted for $1 \mathrm{~h}$ with goat anti-mouse IgG $(\mathrm{H}+\mathrm{L} ; 1: 200$, Earthox, E032220) in a box with a constant temperature of $37^{\circ} \mathrm{C}$. Sections were re-dyed with DAPI (Vector Laboratories, California, USA), washed, and mounted with an antifading medium before undergoing microscopic observations with a laser confocal microscope.

\section{Western blotting}

The esophageal tissues were homogenized in lysis buffer containing proteinase inhibitors (Jianglai Biotech, Shanghai, China) $)^{53}$. The lysates were centrifuged at $12,000 \mathrm{rpm}$ for $10 \mathrm{~min}$ at $4{ }^{\circ} \mathrm{C}$, and the concentrations of the proteins were determined with a protein kit (Bio-Rad Laboratories Inc., Hercules, CA, USA). Twenty micrograms of each esophageal protein was electrophoresed on a $5 \%$ sodium dodecyl sulfate-polyacrylamide gel and then transferred to polyvinylidene difluoride membranes (Millipore, Bedford, MA, USA). The membranes were blocked with $5 \%$ skim milk in Tris-buffered saline including $0.1 \%$ Tween- 20 for $1 \mathrm{~h}$ at room temperature. The membranes were then incubated with primary anti-CD71 (Santa Cruz Biotechnology; 1:200), anti-CK14 (Abcam; 1:100), anti-PCNA (Santa Cruz Biotechnology, 1:100), or anti-integrin $\alpha 6$ (Santa Cruz Biotechnology, 1:100) antibodies overnight at $4^{\circ} \mathrm{C}$ and subsequently incubated with horseradish peroxidase-conjugated secondary antibodies for $1 \mathrm{~h}$ at room temperature. Specific protein bands were developed using an enhanced chemiluminescence detection kit (Amersham, Piscataway, NJ, USA). The membranes were probed with $\beta$-actin antibody (Abcam), and the intensity of each protein band was normalized to $\beta$-actin.

\section{Enzyme-linked immunosorbent assay}

Two milliliters of blood drawn from the rat's tail vein was centrifuged at a rate $3000 \mathrm{r} / \mathrm{min}$, and the serum was separated. The concentrations of IL- $1 \beta$, IL- 8 , and TNF- $\alpha$ were tested using enzyme-linked immunosorbent assays

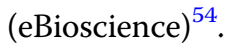

\section{Statistical analysis}

The data are expressed as the mean \pm SEM. Student's $t$ test and the nonparametric Mann-Whitney $U$ test were used to assess the differences, and $P<0.05$ was defined as a significant difference.

\footnotetext{
Acknowledgements

This work was co-supported by the College Students' Innovative Entrepreneurial Training Funded Projects in Heilongjiang Province (Grant \#201510226057), the National Natural Science Foundation of China (Grant \#81370557), the Scientific Project of the Health Bureau of Heilongjiang Province (Grant \#2013052), and the Scientific and Technical Project of Education Department of Heilongjiang Province (Grant \#12531293).
}

Conflict of interest

The authors declare that they have no conflict of interest.

\section{Publisher's note}

Springer Nature remains neutral with regard to jurisdictional claims in published maps and institutional affiliations.

Received: 29 January 2018 Revised: 9 May 2018 Accepted: 22 May 2018 Published online: 03 July 2018

References

1. Yu, Y., Guan, H., Dong, Y., Xing, L. \& Li, X. Advances in dosimetry and biological predictors of radiation-induced esophagitis. Onco. Targets Ther. 9, 597-603 (2016).

2. Tandon, S. et al. The use of adaptive intensity-modulated radiotherapy in the treatment of small-cell carcinoma lung refractory to chemotherapy in a patient with preexisting interstitial lung disease. Lung India 35, 54-57 (2018).

3. Challand, T., Thureau, S., Dubray, B. \& Giraud, P. Esophageal toxicity of radiation therapy: clinical risk factors and management. Cancer Radiother. 16, 364-371 (2012).

4. Zhang, W. et al. External beam radiation and high-dose-rate brachytherapy for elderly patients with gastroesophageal junction adenocarcinoma. J. Contemp. Brachyther. 9, 330-337 (2017).

5. Verma, V., Simone, C. B. \& Werner-Wasik, M. Acute and late toxicities of concurrent chemoradiotherapy for locally-advanced non-small cell lung cancer. Cancers (Basel) 9, E120 (2017).

6. Palma, D. A. et al. Predicting esophagitis after chemoradiation therapy for nonsmall cell lung cancer: an individual patient data meta-analysis. Int. J. Radiat. Oncol. Biol. Phys. 87, 690-696 (2013).

7. Kim, D. B., Bowers, S. \& Thomas, M. Black and white esophagus: rare presentations of severe esophageal ischemia. Semin. Thorac. Cardiovasc. Surg. 29, 256-259 (2017).

8. Citrin, D. et al. Radioprotectors and mitigators of radiation-induced normal tissue injury. Oncologist 15, 360-371 (2010).

9. Kim, K. S. et al. Radiation-induced esophagitis in vivo and in vitro reveals that epidermal growth factor is a potential candidate for therapeutic intervention strategy. Int. J. Radiat. Oncol. Biol. Phys. 95, 1032-1041 (2016).

10. Jiang, T. et al. In vitro expansion impaired the stemness of early passage mesenchymal stem cells for treatment of cartilage defects. Cell Death Dis. 8 , e2851 (2017)

11. Rodgers, K. \& Jadhav, S. S. The application of mesenchymal stem cells to treat thermal and radiation burns. Adv. Drug Deliv. Rev. 123, 75-81 (2018).

12. Gong, W. et al. Mesenchymal stem cells stimulate intestinal stem cells to repair radiation-induced intestinal injury. Cell Death Dis. 7, e2387 (2016).

13. Epperly, M. W. et al. Bone marrow origin of cells with capacity for homing and differentiation to esophageal squamous epithelium. Radiat. Res. 162, 233-240 (2004).

14. Song, B. et al. Bladder smooth muscle cells differentiation from dental pulp stem cells: future potential for bladder tissue engineering. Stem Cells Int. 2016, 6979368 (2016).

15. Goorha, S. \& Reiter, L. T. Culturing and neuronal differentiation of human dental pulp stem cells. Curr. Protoc. Hum. Genet. 92, 21.6.1-21.6.10 (2017).

16. Zhan, F. L., Liu, X. Y. \& Wang, X. B. The role of microRNA-143-5p in the differentiation of dental pulp stem cells into odontoblasts by targeting Runx2 via the OPG/RANKL signaling pathway. J. Cell. Biochem. 119, 536-546 (2018)

17. Tatullo, M., Marrelli, M., Shakesheff, K. M. \& White, L. J. Dental pulp stem cells: function, isolation and applications in regenerative medicine. J. Tissue Eng. Regen. Med. 9, 1205-1216 (2015).

18. d'Aquino, R. et al. Human postnatal dental pulp cells co-differentiate into osteoblasts and endotheliocytes: a pivotal synergy leading to adult bone tissue formation. Cell Death Differ. 14, 1162-1171 (2007).

19. Nozaki, T. \& Ohura, K. Gene expression profile of dental pulp cells during differentiation into an adipocyte lineage. J. Pharmacol. Sci. 115, 354-363 (2011).

20. Mori, G. et al. Dental pulp stem cells: osteogenic differentiation and gene expression. Ann. NY Acad. Sci. 1237, 47-52 (2011). 
21. Hashemi-Beni, B., Khoroushi, M., Foroughi, M. R., Karbasi, S. \& Khademi, A. A. Tissue engineering: dentin-pulp complex regeneration approaches (a review). Tissue Cell 49, 552-564 (2017).

22. Cao, X. F. et al. Therapeutic effects of hepatocyte growth factor-overexpressing dental pulp stem cells on liver cirrhosis in a rat model. Sci. Rep. 7, 15812 (2017).

23. Nath, R. et al. Dosimetry of interstitial brachytherapy sources: recommendations of the AAPM Radiation Therapy Committee Task Group No. 43. American Association of Physicists in Medicine. Med. Phys. 22, 209-234 (1995)

24. Rivard, M. J. et al. Update of AAPM Task Group No. 43 Report: a revised AAPM protocol for brachytherapy dose calculations. Med. Phys. 31, 633-674 (2004).

25. Zhang, L. et al. SOX17 regulates conversion of human fibroblasts into endothelial cells and erythroblasts by dedifferentiation into CD34(+) progenitor cells. Circulation 135, 2505-2523 (2017).

26. Khazaei, M., Ahuja, C. S. \& Fehlings, M. G. Induced pluripotent stem cells for traumatic spinal cord injury. Front. Cell Dev. Biol. 4, 152 (2016).

27. Viña-Almunia, J. et al. Influence of partial $\mathrm{O}_{2}$ pressure on the adhesion, proliferation, and osteogenic differentiation of human dental pulp stem cells on $\beta$-tricalcium phosphate scaffold. Int. J. Oral Maxillofac. Implants 32, 1251-1256 (2017).

28. Coskun, $\mathrm{H}$. et al. Lycopene in the prevention of radiation-induced esophagitis. Nutr. Cancer 69, 319-329 (2017).

29. Martínez-Sarrà, E. et al. Human dental pulp pluripotent-like stem cells promote wound healing and muscle regeneration. Stem Cell Res. Ther. 8, 175 (2017).

30. Botelho, J., Cavacas, M. A., Machado, V. \& Mendes, J. J. Dental stem cells: recent progresses in tissue engineering and regenerative medicine. Ann. Med. 49, 644-651 (2017)

31. Werle, S. B. et al. Carious deciduous teeth are a potential source for dental pulp stem cells. Clin. Oral Investig. 20, 75-81 (2016).

32. Davies, O. G., Cooper, P. R., Shelton, R. M., Smith, A. J. \& Scheven, B. A. A comparison of the in vitro mineralisation and dentinogenic potential of mesenchymal stem cells derived from adipose tissue, bone marrow and dental pulp. J. Bone Miner. Metab. 33, 371-382 (2015).

33. Anitua, E., Troya, M. \& Zalduendo, M. Progress in the use of dental pulp stem cells in regenerative medicine. Cytotherapy 20, 479-498 (2018).

34. Shen, L. et al. Therapeutic effect of compound of white peony root oral liquids on radiation-induced esophageal toxicity via the expression of EGF and TGFbeta1. Biomed. Rep. 1, 308-314 (2013).

35. Epperly, M. W. et al. Intraesophageal administration of GS-nitroxide (JP4-039) protects against ionizing irradiation-induced esophagitis. Vivo 24, 811-819 (2010).

36. Huang, E. X. et al. Independent test of a model to predict severe acute esophagitis. Adv. Radiat. Oncol. 2, 37-43 (2017).

37. Yang, M. et al. A pilot study of intraluminal brachytherapy using ${ }^{125}$ I seed strand for locally advanced pancreatic ductal adenocarcinoma with obstructive jaundice. Brachytherapy 15, 859-864 (2016).
38. Oellers, P. et al. Efficacy and safety of low-dose iodine plaque brachytherapy for juxtapapillary choroidal melanoma. Am. J. Ophthalmol. 186, 32-40 (2018).

39. Zhang, W. et al. Efficacy and safety of iodine-125 radioactive seeds brachytherapy for advanced non-small cell lung cancer-a meta-analysis. Brachytherapy 17, 439-448 (2018).

40. Baker, S. \& Fairchild, A. Radiation-induced esophagitis in lung cancer. Lung Cancer (Auckl.) 7, 119-127 (2016).

41. Zamora, R., Ravuri, S. K., Plock, J. A., Vodovotz, Y. \& Gorantla, V. S. Differential inflammatory networks distinguish responses to bone marrow-derived versus adipose-derived mesenchymal stem cell therapies in vascularized composite allotransplantation. J. Trauma Acute Care Surg. 83, S50-SS58 (2017).

42. Tarnawski, A. S., \& Ahluwalia, A. Molecular mechanisms of epithelial regeneration and neovascularization during healing of gastric and esophageal ulcers. Curr. Med. Chem. 19, 16-27 (2012).

43. Witko-Sarsat, V. \& Ohayon, D. Proliferating cell nuclear antigen in neutrophil fate. Immunol. Rev. 273, 344-356 (2016).

44. Giampietri, C. et al. c-Flip overexpression affects satellite cell proliferation and promotes skeletal muscle aging. Cell Death Dis. 1, e38 (2010).

45. Croagh, D., Phillips, W. A., Redvers, R., Thomas, R. J. \& Kaur, P. Identification of candidate murine esophageal stem cells using a combination of cell kinetic studies and cell surface markers. Stem Cells 25, 313-318 (2007).

46. Croagh, D., Thomas, R. J., Phillips, W. A. \& Kaur, P. Esophageal stem cells-a review of their identification and characterization. Stem Cell Rev. 4, 261-268 (2008).

47. Herrera-Imbroda, B. et al. An immunohistochemical study of cytokeratins distribution of the human adult male and female urethra. Histol. Histopathol. 32, 283-291 (2017).

48. Dabrowska, S. et al. Imaging of extracellular vesicles derived from human bone marrow mesenchymal stem cells using fluorescent and magnetic labels. Int. J. Nanomed. 13, 1653-1664 (2018).

49. Di Scipio, F., Sprio, A. E., Carere, M. E., Yang, Z. \& Berta, G. N. A simple protocol to isolate, characterize, and expand dental pulp stem cells. Methods Mol. Biol. 1553, 1-13 (2017).

50. Qian, D. et al. Inhibition of human positive cofactor 4 radiosensitizes human esophageal squmaous cell carcinoma cells by suppressing XLF-mediated nonhomologous end joining. Cell Death Dis. 5, e1461 (2014).

51. Raggi, M. et al. Successful evaluation of a new animal model using mice for esophageal adenocarcinoma. Lange. Arch. Surg. 395, 347-350 (2010).

52. Zhang, C. et al. Dysregulation of PARP1 is involved in development of Barrett's esophagus. World J. Gastroenterol. 24, 982-991 (2018).

53. Shizhu, J. et al. Bone marrow mononuclear cell transplant therapy in mice with CCl4-induced acute liver failure. Turk. J. Gastroenterol. 23, 344-352 (2012).

54. Wright, B. L. et al. Normalized serum eosinophil peroxidase levels are inversely correlated with esophageal eosinophilia in eosinophilic esophagitis. Dis. Esophagus 31, 45-51 (2018). 